\title{
PEMANFAatan BiJI ASAM JaWA (TAMARINDUS INDICA) SEBAgai Koagulan Alami dalam Pengolahan Limbah Cair Industri FARMASI
}

\author{
Dyah Dwi Poerwanto, ${ }^{1}$ Eko Prabowo Hadisantoso,,${ }^{1 *}$ Dan SoEHartini \\ ISNAINI. $^{2}$ \\ ${ }^{1}$ Jurusan Kimia, Fakultas Sains dan Teknologi, UIN Sunan Gunung Djati Bandung, Jl. A.H. Nasution No. \\ 105 Cipadung, Bandung 40614 \\ ${ }^{2}$ Pusat Sumber Daya Air Tanah dan Geologi Lingkungan, Jl. Diponegoro No. 57, Bandung 40122 \\ * email korespondensi: ekopra05@gmail.com
}

\begin{abstract}
ABSTRAK. Telah dilakukan penelitian pemanfaatan biji asam jawa dalam pengolahan limbag cair industri farmasi dengan metoda koagulasi. Koagulasi dan flokulasi merupakan metode pengolahan air untuk limbah yang bersifat koloid. Biji asam jawa mengandung tanin sebesar 20,2 \% yang bersifat sebagai koagulan dan polimer alami seperti pati sebesar 30,1\% yang berfungsi sebagai flokulan. Penelitian ini diawali dengan preparasi koagulan dimana biji asam jawa yang telah dibersihkan ditumbuk hingga menjadi serbuk lalu diayak dengan ayakan tepung. Selanjutnya sampel air limbah ditambahkan koagulan dengan variasi dosis yaitu 1, 3, 5, 7, 9, dan $11 \mathrm{gram} / 500 \mathrm{~mL}$ sampel air limbah, lalu diaduk dengan kecepatan cepat 3 menit dan kecepatan lambat 12 menit, kemudian diendapkan 12 menit. Filtrat hasil koagulasi dianalisis berdasarkan Kep-51/MENLH/10/1995 tentang baku mutu limbah cair industri farmasi. Dari hasil penelitian ini diketahui bahwa kemampuan biji asam jawa cukup baik sebagai koagulan untuk memperbaiki nilai $\mathbf{p H}$, menurunkan konsentrasi TSS pada dosis optimum $1 \mathrm{~g} / 500 \mathrm{~mL}$, BOD pada dosis optimum 7 g/500mL, serta $\mathrm{NH}_{4}{ }^{+}$pada dosis optimum 3 g/500 mL. Namun, koagulan ini belum dapat digunakan untuk menurunkan konsentrasi COD dan fenol dalam limbah cair industri farmasi.
\end{abstract}

Kata kunci: biji asam jawa, limbah industri farmasi, koagulasi, flokulasi, variasi dosis koagulan.

\section{Latar Belakang}

Air limbah industri farmasi merupakan salah satu sumber pencemaran yang potensial. Oleh karena itu, air limbah tersebut perlu diolah terlebih dahulu sebelum di buang ke badan air. Untuk pengolahan air limbah industri farmasi umumnya menggunakan teknologi pengolahan air limbah lumpur aktif yang kurang ekonomis karena biaya operasional cukup besar dan kontrol operasionalnya cukup sulit. ${ }^{[1]}$ Untuk mengatasi hal tersebut maka perlu dikembangkan teknologi pengolahan air limbah yang mudah pengoperasiannya, ekonomis, dan memenuhi standar lingkungan.

Alternatif dari penggunaan koagulan sintetik yaitu pemanfaatan biokoagulan yang berasal dari bahan-bahan yang tersedia di alam yang salah satunya yaitu biji asam jawa (Tamarindus indica) yang selama ini hanya sebagai limbah yang jarang dimanfaatkan dan perlu dikembangkan lebih lanjut untuk pengolahan limbah cair yang lebih ekonomis dan ramah lingkungan.

Telah dilakukan penelitian terhadap tanaman yang memiliki potensi sebagai biokoagulan diantaranya pemanfaatan biji kelor pada proses koagulasi dalam pengolahan limbah cair industri tahu dengan penyisihan turbiditas $89,42 \%$, TSS $98,73 \%$, dan COD 69,58\%. ${ }^{[2]}$ Lalu pemanfaatan biji asam jawa sebagai koagulan alternatif dalam proses menurunkan COD dan BOD pada limbah cair industri tempe dimana diperoleh secara berturut-turut efisiensi removal BOD sebesar 82,62 \%, COD sebesar 81,72 \%, dan TSS sebesar $76,47 \%{ }^{[3]}$ serta koagulan alami dari biji trembesi, biji kelor, dan kacang merah dalam proses penurunan kadar fosfat pada limbah cair industri pupuk yang mencapai 73,31\%. ${ }^{[4]}$

Tujuan penelitian ini adalah untuk mengetahui kemampuan biji asam jawa sebagai koagulan alami dalam memperbaiki kualitas air limbah industri farmasi dan mengetahui pengaruh biji asam jawa terhadap parameter kualitas limbah cair industri farmasi, yang meliputi: TSS, pH, COD, BOD, fenol, dan $\mathrm{NH}_{4}{ }^{+}$. Pemilihan biji asam jawa sebagai koagulan alami untuk pengolahan air limbah 
didasarkan pada kandungan dari biji asam jawa. Kandungan biji asam jawa yaitu polisakarida dan tanin merupakan koagulan alami yang lebih ramah lingkungan bila dibandingkan dengan koagulan organik dan anorganik lainnya untuk pengolahan air limbah. ${ }^{[5]}$

\section{Metode Penelitian}

\section{Preparasi Koagulan}

Biji asam jawa dipisahkan dari dagingnya dan dibersihkan. Kemudian dipanaskan menggunakan oven pada suhu $105^{\circ} \mathrm{C}$ selama 60 menit lalu ditumbuk hingga berbentuk serbuk dan diayak menggunakan ayakan tepung untuk menghomogenkan dan agar luas permukaan koagulan sama serta disimpan dalam desikator. Serbuk inilah yang selanjutnya digunakan sebagai koagulan dalam proses koagulasi.

\section{Pengambilan Sampel}

Sampel diperoleh dari air limbah salah satu industri farmasi di Bandung. Teknik pengambilan sampel yaitu diambil secara langsung sebanyak $5000 \mathrm{~mL}$ ke dalam jerigen mengikuti prosedur pengambilan sampel di industri tersebut dimana sebelumnya limbah ditampung di dalam bak penampungan setiap 1 jam yang kemudian diambil untuk analisis.

\section{Proses Koagulasi}

Air limbah yang telah dianalisis awal dimasukkan ke dalam lima gelas kimia masingmasing sebanyak $500 \mathrm{~mL}$ kemudian ditambahkan serbuk biji asam jawa dengan variasi dosis yaitu 1, 3, 5, 7, 9, dan 11 gram. Lalu diaduk dengan kecepatan cepat selama 3 menit, dilanjutkan kecepatan lambat selama 12 menit, kemudian diendapkan selama 60 menit. Lalu disaring dengan kertas saring Whatman No 1. Filtrat kemudian diambil untuk dianalisis parameter TSS, $\mathrm{pH}, \mathrm{COD}, \mathrm{BOD}$, fenol, dan $\mathrm{NH}_{4}{ }^{+}$. Metoda pengujuan COD, TSS, fenol, dan $\mathrm{NH}_{4}{ }^{+}$berdasarkan Standar Methods APHA, E. A., \& Lenore, C (1995) serta pengujian $\mathrm{pH}$ (SNI) 6989.11:2004 dan BOD (SNI) 6989.72:2009.

\section{Hasil dan Pembahasan}

\section{Koaguan Biji Asam Jawa}

Koagulan biji asam jawa yang digunakan adalah berbentuk serbuk. Serbuk biji asam jawa diperoleh dengan cara dipanaskan dan ditumbuk. Tujuan pemanasan adalah untuk mempermudah dalam penumbukan biji asam karena setelah pemanasan, kadar air pada biji asam berkurang dan warna cangkangnya menjadi lebih gelap sehingga mudah dilepas. Setelah ditumbuk, serbuk diayak menggunakan ayakan tepung untuk menghomogenkan dan agar luas permukaan koagulan sama. Sebelum digunakan, serbuk tersebut disimpan di dalam desikator untuk menghindari uap air. Biji asam jawa dapat digunakan sebagai koagulan pada proses koagulasi karena pertimbangan kandungan tannin dalam biji tersebut serta polimer alami seperti pati berfungsi sebagai flokulan. Tanin merupakan salah satu senyawa metabolit sekunder yang terdapat pada tanaman dan disintesis oleh tanaman sedangkan pati merupakan polisakarida yang banyak terdapat pada sebagian besar tumbuhan dan dapat larut dalam air membentuk larutan koloid. ${ }^{[6]}$

\section{Pengaruh Variasi Dosis Koagulan Terhadap Penyisihan TSS}

Nilai TSS limbah industri farmasi sebelum perlakuan menunjukkan nilai $1 \mathrm{mg} / \mathrm{L}$ TSS. Nilai tersebut sudah dibawah nilai maksimum untuk parameter kualitas air limbah industri farmasi menurut Kep51/MENLH/10/1995 yaitu $75 \mathrm{mg} / \mathrm{L}$. Pada penelitian ini, dosis optimum untuk menurunkan kadar TSS pada limbah farmasi adalah $1 \mathrm{~g} / 500 \mathrm{~mL}$ serbuk biji asam jawa yang dapat diketahui pada dosis $1,3,5,7,9$, dan 11 gram per $500 \mathrm{~mL}$ limbah cair industri farmasi dapat menurunkan masing-masing menjadi 0,030 mg/L;0,038 mg/L; 0,162 mg/L;0,206 $\mathrm{mg} / \mathrm{L} ; 0,048 \mathrm{mg} / \mathrm{L}$; dan $0,028 \mathrm{mg} / \mathrm{L}$. Grafik hubungan variasi dosis koagulan biji asam jawa dengan nilai TSS dapat dilihat pada Gambar 1.

Semakin banyak koagulan yang ditambahkan maka kemampuan untuk menjernihkan limbah cair industri farmasi menjadi jenuh sehingga koagulan yang tersisa akan mengotori larutan yang ada. Selain itu, pada saat proses koagulasi dikhawatirkan proses koagulasi sampel belum mencapai keadaan setimbang sehingga ketika koagulasi telah mencapai dosis optimum, konsentrasi TSS mengalami penurunan kembali. 


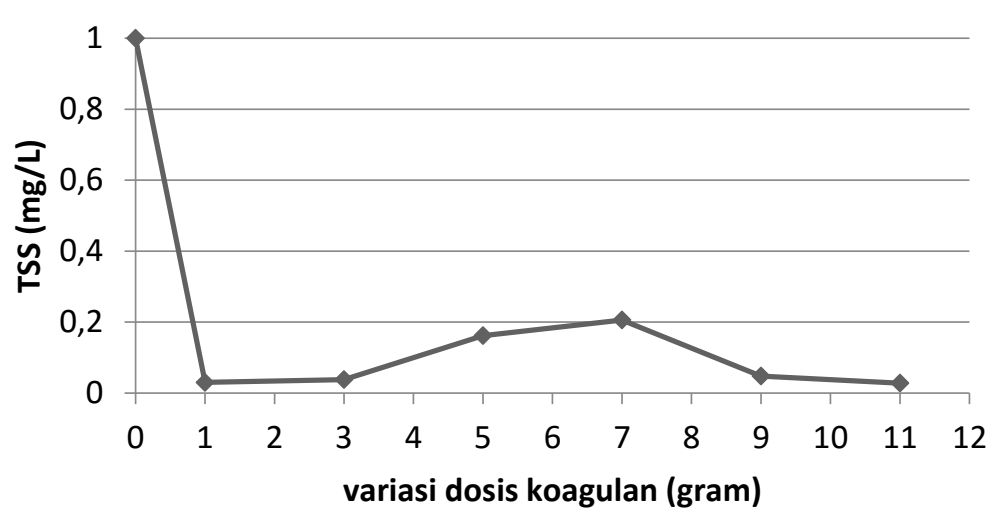

Gambar 1. Hubungan Variasi Dosis Koagulan dengan Nilai TSS

\section{Pengaruh Variasi Dosis Koagulan Terhadap pH}

Biji asam jawa memiliki kadar $\mathrm{pH}$ yang asam sekitar 2-4 sehingga lebih cocok digunakan untuk pengolahan limbah cair yang memiliki $\mathrm{pH}$ asam. Pada penelitian ini dapat dilihat hasil penurunan $\mathrm{pH}$ yang sangat signifikan. Kadar $\mathrm{pH}$ pada limbah industri farmasi sudah sesuai dengan Kep51/MENLH/10/1995 yaitu 7,92. Pada penelitian ini, semakin banyak koagulan yang ditambahkan maka nilai $\mathrm{pH}$ semakin naik yaitu dosis $1,3,5,7,9$, dan 11 gram per $500 \mathrm{~mL}$ limbah cair industri farmasi dapat menaikkan $\mathrm{pH}$ masing-masing menjadi 4,$53 ; 4,63 ; 4,77$; 4,$84 ; 5,74$; dan 5,82. Grafik hubungan variasi dosis koagulan biji asam jawa dengan $\mathrm{pH}$ dapat dilihat pada Gambar 2.

Pengaruh Variasi Dosis Koagulan Terhadap Konsentrasi COD
Konsentrasi COD pada limbah cair industri farmasi sebelum pengolahan menunjukkan nilai $33 \mathrm{mg} / \mathrm{L}$. Menurut Kep51/MENLH/10/1995 batas maksimum konsentrasi COD dalam limbah industri farmasi adalah $150 \mathrm{mg} / \mathrm{L}$ sehingga limbah cair ini sudah memiliki nilai COD di bawah nilai maksimum. Kenaikan konsentrasi COD dapat diketahui pada dosis $1,3,5,7,9$, dan 11 gram per $500 \mathrm{~mL}$ limbah cair industri farmasi menaikkan konsentrasi COD masing-masing 280,5 mg/L; $660 \mathrm{mg} / \mathrm{L} ; 924 \mathrm{mg} / \mathrm{L} ; 1386 \mathrm{mg} / \mathrm{L} ; 2409 \mathrm{mg} / \mathrm{L}$; dan $2310 \mathrm{mg} / \mathrm{L}$, yang ditunjukkan pada Gambar 3.

Konsentrasi COD sebelum penambahan koagulan sudah berada dibawah batas maksimum untuk konsentrasi COD limbah cair industri farmasi. Namun, setelah penambahan koagulan, konsentrasi COD malah semakin naik. Hal ini disebabkan bahwa biokoagulan yang digunakan berasal dari senyawa organik sehingga koagulan tersebut menjadi bahan baku

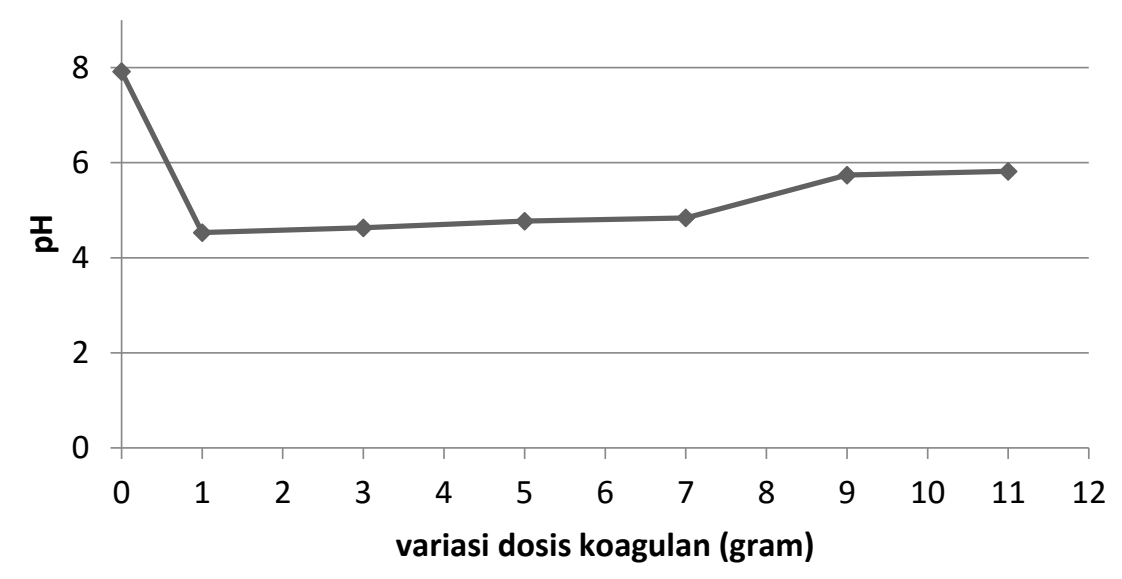

Gambar 2. Hubungan Variasi Dosis Koagulan dengan $\mathrm{pH}$ 


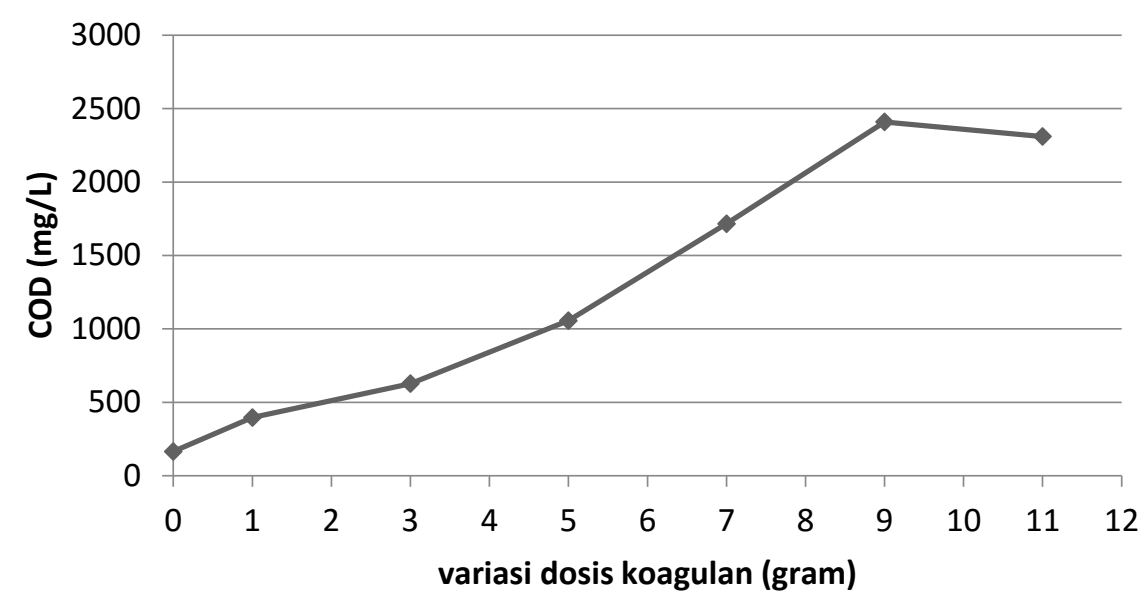

Gambar 3. Hubungan Variasi Dosis Koagulan dengan COD

untuk oksidasi. Selain itu, COD dalam air limbah tersebut sedikit sehingga koagulan dengan muatan negatif yang masuk tidak dapat menyelubungi seluruh koloid yang ada pada air limbah. Koagulan yang masuk ke dalam air limbah menjadi berlebih dan menyebabkan meningkatnya nilai COD.

\section{Pengaruh Variasi Dosis Koagulan Terhadap Konsentrasi BOD}

Konsentrasi BOD pada limbah cair industri farmasi sebelum pengolahan menunjukkan nilai 30,55 mg/L. Menurut Kep51/MENLH/10/1995 batas maksimum konsentrasi COD dalam limbah industri farmasi adalah $75 \mathrm{mg} / \mathrm{L}$ sehingga limbah cair ini sudah memiliki nilai BOD dibawah nilai maksimum. Penurunan konsentrasi BOD dapat diketahui pada dosis $1,3,5,7,9$, dan 11 gram per $500 \mathrm{~mL}$ limbah cair industri farmasi menurunkan konsentrasi BOD masing-masing 30,41 mg/L;
$14,19 \mathrm{mg} / \mathrm{L} ; 13,71 \mathrm{mg} / \mathrm{L} ; 13,22 \mathrm{mg} / \mathrm{L} ; 17,75$ $\mathrm{mg} / \mathrm{L}$; dan $8,98 \mathrm{mg} / \mathrm{L}$. Grafik hubungan variasi dosis koagulan biji asam jawa dengan BOD dapat dilihat pada Gambar 4.

Dosis biji asam jawa yang terlalu banyak mengakibatkan kemampuan penurunan kadar BOD limbah cair industri farmasi menjadi jenuh. Selain itu, pada dosis koagulan 9 gram terjadi kenaikan konsentrasi BOD. Hal ini berhubungan dengan kandungan biokoagulan biji asam jawa yang memiliki sifat antimikroba yang dapat mengakibatkan kematian mikroorganisme yang berperan untuk mendegradasikan bahan organik dalam sampel. [7] Dosis optimum pada penelitian ini yaitu 7 $\mathrm{g} / 500 \mathrm{~mL}$ koagulan dimana dapat menurunkan konsentrasi BOD menjadi 13,22 mg/L.

\section{Pengaruh Variasi Dosis Koagulan Terhadap Konsentrasi Fenol}

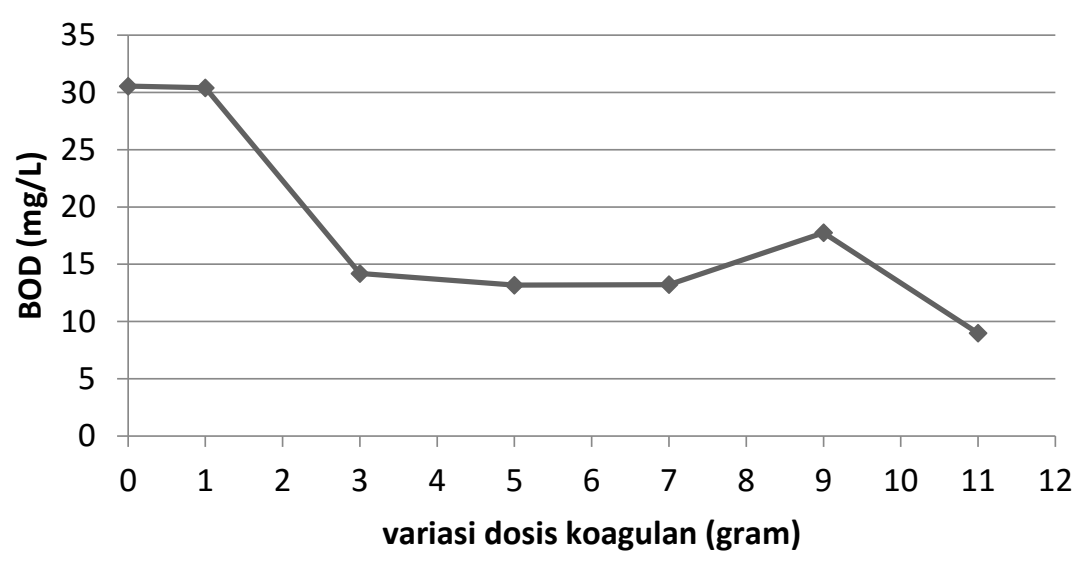

Gambar 4. Hubungan Variasi Dosis Koagulan dengan BOD 
Konsentrasi fenol pada limbah cair industri farmasi sebelum pengolahan menunjukkan nilai 3,897 mg/L. Menurut Kep51/MENLH/10/1995 batas maksimum konsentrasi fenol dalam limbah industri farmasi adalah $1,0 \mathrm{mg} / \mathrm{L}$ sehingga limbah cair ini memiliki konsentrasi fenol di atas ambang batas maksimum. Kenaikan dan penurunan konsentrasi fenol dapat diketahui pada dosis 1, $3,5,7,9$, dan 11 gram per $500 \mathrm{~mL}$ limbah cair industri farmasi menaikkan dan menurunkan konsentrasi fenol masing-masing 4,328 mg/L; 4,670 mg/L; 4,735 mg/L; 4,829 mg/L; 4,400 $\mathrm{mg} / \mathrm{L} ;$ dan 2,287 mg/L.

Dari Gambar 5 dikerahui bahwa konsentrasi fenol yang semakin tinggi setelah penambahan koagulan menunjukkan bahwa koagulan ini tidak cocok digunakan untuk memperbaiki kualitas air limbah cair industri farmasi yang mengandung fenol. Jika pada parameter sebelumnya dapat mengurangi kadar pencemar air limbah, maka untuk parameter fenol ini malah memperburuk kualitas air limbah yang sebelumnya sudah di atas ambang batas maksimum. Dengan demikian, jika koagulan ini ditambahkan pada limbah cair industri farmasi, maka akan mengurangi kualitas air limbah (fenol naik) walaupun untuk parameter yang lain koagulan ini dapat memperbaiki kualitas air limbahnya. Kenaikan konsentrasi fenol disebabkan karena kandungan tanin dalam biji asam jawa yang tergolong senyawa polifenol juga menyebabkan kadar fenol semakin meningkat. [8]

\section{Pengaruh Variasi Dosis Koagulan Terhadap Konsentrasi Amonium}

Konsentrasi amonium pada limbah cair industri farmasi sebelum pengolahan menunjukkan nilai $40 \mathrm{mg} / \mathrm{L}$. Menurut Kep51/MENLH/10/1995 batas maksimum konsentrasi N-total dalam limbah industri farmasi adalah $30 \mathrm{mg} / \mathrm{L}$ sehingga limbah cair ini memiliki konsentrasi $\mathrm{NH}_{4}^{+}$di atas ambang batas maksimum (Gambar 6). Penurunan

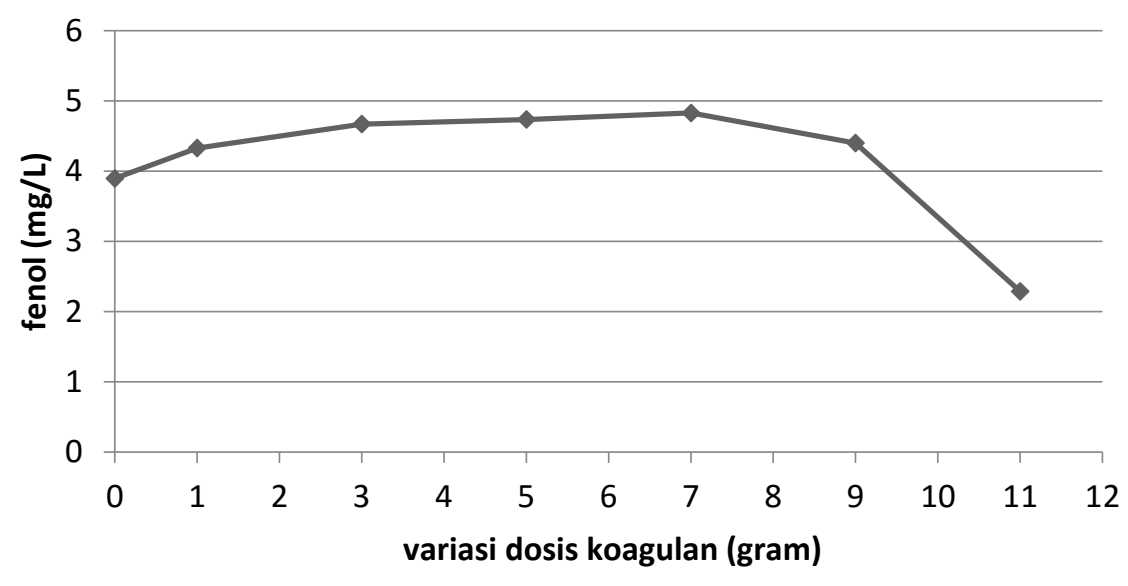

Gambar 5. Hubungan Variasi Dosis Koagulan dengan Konsentrasi Fenol

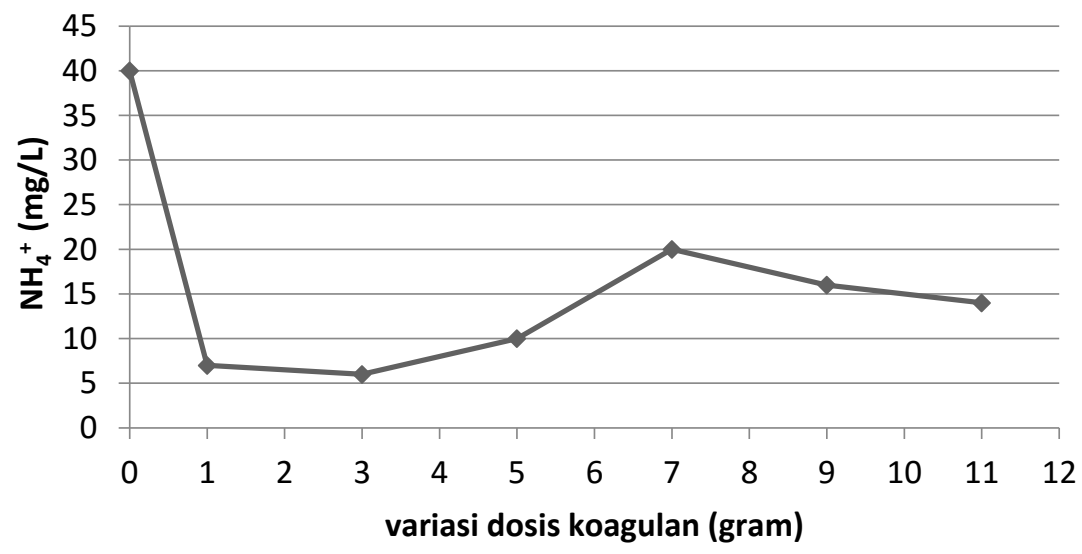

Gambar 6. Hubungan Variasi Dosis Koagulan dengan Konsentrasi Ammonium 
konsentrasi $\mathrm{NH}_{4}{ }^{+}$dapat diketahui pada dosis 1 , $3,5,7,9$, dan 11 gram per $500 \mathrm{~mL}$ limbah cair industri farmasi menurunkan konsentrasi $\mathrm{NH}_{4}{ }^{+}$ masing-masing $7 \mathrm{mg} / \mathrm{L} ; 6 \mathrm{mg} / \mathrm{L} ; 10 \mathrm{mg} / \mathrm{L} ; 20$ $\mathrm{mg} / \mathrm{L} ; 16 \mathrm{mg} / \mathrm{L}$; dan $14 \mathrm{mg} / \mathrm{L}$. Pada dosis koagulan 3 gram ke 5 gram sampai ke 7 gram, konsentrasi NH4+ meningkat kemudian menurun kembali. Hal ini disebabkan kelebihan dosis koagulan yang ditambahkan ke dalam sampel sehingga koagulan tidak dapat menyelubungi seluruh koloid pada air limbah dan menyebabkan meningkatnya konsentrasi $\mathrm{NH}_{4}{ }^{+}$.

\section{Kesimpulan}

Hasil penelitian menunjukkan bahwa koagulan dari biji asam jawa dapat menangani limbah cair industri farmasi untuk parameter TSS, pH, BOD, dan $\mathrm{NH} 4+$, namun untuk parameter COD dan fenol, koagulan ini belum dapat menurunkan konsentrasi sesuai KepMenLH No. 51 tahun 1995 serta kemampuan biji asam jawa cukup baik sebagai koagulan untuk memperbaiki nilai $\mathrm{pH}$, menurunkan konsentrasi TSS pada dosis optimum $1 \mathrm{~g} / 500 \mathrm{~mL}$, BOD pada dosis optimum $7 \mathrm{~g} / 500 \mathrm{~mL}$, serta NH4+ pada dosis optimum $3 \mathrm{~g} / 500 \mathrm{~mL}$. Namun, koagulan ini belum dapat digunakan untuk menurunkan konsentrasi COD dan fenol dalam limbah cair industri farmasi.

\section{Referensi}

[1] Muliartha, IK. 2004. Pedoman Teknis Pengelolaan Limbah Cair Industri Kecil. Jakarta: PT. Envirotekno Karya Mandiri.

[2] Putra, R., Lebu, B., Munthe, D., dan Rambe, A.M. 2013. Pemanfaatan Biji Kelor Sebagai Koagulan Pada Proses Koagulasi Limbah Cair Industri Tahu Dengan Menggunakan Jar Test. Jurnal Teknik Kimia USU. Vol 2, nomor 2 : 2831.

[3] Ramadhani, GI, Moesriati A. 2013. Pemanfaatan Biji Asam Jawa (Tamarindus indica) Sebagai Koagulan Alternatif dalam Proses Menurunkan Kadar COD dan BOD dengan Studi Kasus pada Limbah Cair Industri Tempe. Jurnal Teknik ITS. Vol II, Nomor 1 : D$22-\mathrm{D} 26$.

[4] Utami, SDR. Uji Kemampuan Koagulan Alami Dari Biji Trembesi, Biji Kelor, dan Kacang Merah Dalam Proses Penurunan Kadar Fosfat Pada Limbah Cair Industri Pupuk. Jurnal Teknik Lingkungan FTSP-ITS.

[5] Enrico, B. 2008. Pemanfaatan Biji Asam Jawa Sebagai Koagulan Alternatif Dalam Proses Penjernihan Limbah Cair Industri Tahu. Medan: Universitas Sumatera Utara. Tesis.

[6] Poedjiadi, A. 2005. Dasar-Dasar Biokimia. Jakarta: UI Press.

[7] Hendrawati. 2013. Penggunaan Biji Asam Jawa (Tamarindus Indica L.) dan Biji Kecipir (Psophocarpus tetragonolobus L.) Sebagai Koagulan Alami Dalam Perbaikan Kualitas Air Tanah. Vol III. Hal 22-33.

[8] Effendi, H. 2003. Telaah Kualitas Air. Yogyakarta: Penerbit KANISIUS 